\title{
Schoolcube: Gamification for Learning Management System through Microsoft SharePoint
}

\author{
Mohd Amir Azmi and Dalbir Singh \\ Research Center for Software Technology and Management (SOFTAM), Faculty of Information Science and Technology, \\ Universiti Kebangsaan Malaysia (UKM), 43600 Bangi, Selangor, Malaysia
}

Correspondence should be addressed to Dalbir Singh; dalbir@ukm.edu.my

Received 16 March 2015; Revised 18 May 2015; Accepted 25 May 2015

Academic Editor: Alexander Pasko

Copyright ( 2015 M. A. Azmi and D. Singh. This is an open access article distributed under the Creative Commons Attribution License, which permits unrestricted use, distribution, and reproduction in any medium, provided the original work is properly cited.

\begin{abstract}
A Learning Management System (LMS) is a system which acts as an integrated platform for the management of the learning process used to facilitate the process of communication between students and instructors. Although LMS is considered an important element in learning, most students do not utilise the system to its fullest extent, finding it more convenient if the activities carried out on the system are done outside the system. These factors have contributed to the issues as to why LMSs are not being used effectively and efficiently. With the accelerating pace of information technology, educational institutions should attempt to revolutionise their teaching techniques. Furthermore, combining gaming concepts can potentially increase the LMS's usability level helping to foster healthy competition among students and increase their interest in their daily learning. With regard to this objective, a prototype was developed as a proof of concept. The prototype is a web-based software and can be accessed via the Internet at all times. The teacher monitors the students' performance through the analysis of test results or tutorials conducted by the system. In conclusion, this study will present the modules that have been built into the system that could improve the overall process of education.
\end{abstract}

\section{Introduction}

Over the years, the education system has shifted from learning in the classroom to learning in cyberspace [1]. Learning Management Systems (LMSs) were created as a response to the need for a suitable platform to facilitate student-teacher interaction in a technology-based environment. At the most basic level, an LMS can be defined as a system that automates the administration, tracking, and scoring of a particular training or education course [2], with common features being content access, content development, and assessment systems available to users amongst other things. Almost all educational institutions currently use a learning management system in their organisation [3], as can be seen in [4], where 99\% of 151 institutions surveyed have an LMS in place. This has created a billion dollar industry expected to grow to over 7 billion USD by 2018 with hundreds of LMS vendors available on the market [5].

It then becomes pertinent for us to continuously improve LMSs to adapt to the current generation of students. The most subtle way of improving LMS is to improve student interaction with the system itself. Many users face difficulties in integrating into the system due to the generational gap that exists between the creation of the system and the environment they were born into. It was found that common reasons for faculties to reduce their use of LMSs tend to be due to it being time-consuming, inflexible, and difficult to use [6]. In some cases, it can be seen that most of the interactive tools available within these LMSs are not as heavily used or highly rated by both educators and students [7]. In a separate study, the trend observed as to the use of interactive tools was that it continues to fall, with LMSs still primarily being used as a document distribution system [8]. There is room for learning applications that enhance student engagement and motivation in their studies [9]. For that reason, this is an opportunity to integrate game-based concepts, which these students are familiar with, such as leveling up and gaining experience into the system through the process known as gamification. 
TABLE 1: Comparisons between 2 popular LMSs available within the market.

\begin{tabular}{|c|c|c|c|c|c|c|c|}
\hline \multirow[b]{2}{*}{ LMS } & \multicolumn{7}{|c|}{ Features } \\
\hline & Discussion tools & $\begin{array}{c}\text { Group } \\
\text { collaboration } \\
\text { tools }\end{array}$ & $\begin{array}{l}\text { Assessment } \\
\text { tools }\end{array}$ & $\begin{array}{c}\text { Social } \\
\text { interaction tools }\end{array}$ & File exchange & Notification & Gamification \\
\hline Moodle 2.0 & Yes & Yes & Yes & Yes & Limited & Limited & Limited \\
\hline Blackboard 9.1 & Yes & Yes & Yes & Limited & Yes & Limited & Limited \\
\hline
\end{tabular}

Gamification is the use of game mechanics and design within nongame environments to create solutions to problems and create motivations for the participants [10]. The foundation of the system being created relies on gamification to motivate users to engage with the system and make it a more enjoyable experience for them.

We developed a gamified LMS in a Microsoft SharePoint based environment to demonstrate the feasibility of the concept of gamification within an LMS. This will combine the features commonly found within LMSs [11], such as content management and discussion boards, with gaming concepts, thereby creating a much more engaging environment for the students and providing more motivation for them to interact with the system.

This paper is split into 2 main sections, the first being the literature review where current researches and trends concerning this topic are explored. The second section is the methodology section where details regarding the system and implementation are reviewed.

\section{Literature Review}

This section presents the research done to assess current trends of LMSs and the concept of gamification.

The first section, regarding the current trends of LMSs, discusses features of current LMSs available within the market as well as issues regarding their functionality and relevance within the current learning environment. The second section, focusing on gamification, defines the concept as well as the factors that allow gamification to appeal to users of the system based on design concepts prevalent in gaming.

2.1. Current Trends of LMSs. The evolution of LMSs began with a simple requirement for file storage and sharing purposes. Over time, the developers of these LMSs started to introduce more features to their system to accommodate the users' requirements. Among the biggest names that are currently dominating the LMS market today are Moodle and Blackboard [12]. Table 1 is a comparison of features found within these LMSs [11], comparing them in terms of their features.

Based on [11], the common features found within these systems include discussion tools, such as discussion forums, assessment tools, which allow the educators to assess users based on their performance, and group collaboration tools, which help users to work together in teams. In terms of social interaction tools, which are tools that allow users to mingle with one another, it is rather limited in Blackboard but fully implemented in Moodle 2.0. The situation is flipped for file exchange tools, which allow users to distribute files to one another, where Blackboard comes out better than Moodle. Both systems tend to be limited in terms of notification features, which allow users to be notified of assignments and notes that might pop up, as well as gamification features, such as leveling up, which are not built-in to the system but rather require system designers to implement it themselves.

The primary purpose of LMSs being introduced was for the system to act as a breeding ground for the interaction between students and teachers, for them to discuss educational topics and exchange ideas through the features in the system such as discussion forums and group collaboration tools [13]. However, the purpose of the systems over the years has been warped and they now act primarily as content management systems rather than a collaborative learning environment $[8,14]$.

On top of that, LMSs present a challenge for the users in terms of their usability and lack of interactivity. The LMSs tend to be static in the way they present themselves to the users, or, in simpler terms, the LMSs do not adjust themselves to the need of the users [15]. Within the current education environment, the system needs to cater to the needs of the students and not the other way around. This is due to the changing nature of the new generation, where the young people are empowered to create knowledge, not just absorb and be more engaged with their education [16].

The challenge that exists with e-learning is not in rebuilding the learning process but rather in how we can design new approaches by utilising the new tools available to us [17]. There are no significant differences in preference for the students between traditional face-to-face learning and online learning options [18]. It begs the question of how we can create another layer to the system that makes the learning experience more fulfilling. This is where we begin to explore new frontiers of learning approaches, with our focus being on gamification.

2.2. Gamification. This section discussing gamification is separated into 3 main topics which are definition, implementation, and impact.

2.2.1. Definition. Gamification by definition is the use of game thinking and mechanics in nongame contexts to engage users in solving problems [10]. In practical terms, it is simply a matter of taking the gameplay mechanics found in games and integrating them with the system we are developing. This is done to create motivations within the users to keep using the 
system in a similar way to how games motivate their players to keep playing.

2.2.2. Implementation of Gamification. There tend to be multiple reasons why games appeal to players, but the underlying reason is essentially that it fulfills or satiates a certain intrinsic need they may have [19]. Due to the myriad of ways games appeal to players, it is important to focus on the features of gameplay mechanics that can best be integrated with an LMS. This is due to the unique challenges that are presented with integrating game mechanics into education. Mirroring games in real life, the mechanics and gameplay need to be simple yet rewarding for the player [20].

One of the biggest driving factors that needs to be considered is the motivation for these students to learn. What drives them to participate in the activity of education? An answer that can be given is a need for achievement [21]. For every activity that the student performs, there needs to be some feeling that they have accomplished something. Achievement is something that games use to motivate their players [22]. The most common example here is the achievement system within the Xbox Live system, a multiplayer gaming service available to Xbox players for a subscription fee [23], with 48 million members in total [24]. Within the Xbox Live system, achievements are implemented in a form of competition where users compete to see who can obtain the highest gamer-score [22]. When it comes to designing the system, the most optimal way of implementing achievements and promoting motivations is by giving rewards, a concept that is argued for in [25-27], to the students for accomplishing tasks such as completing their assignments [28]. This creates an inherent push for the students to complete the tasks assigned to them.

The second driving factor that should be considered is competition. Competition, especially the competitive elements in games, is intrinsically motivating and promotes energetic responses in the classroom [29]. Competition can be regarded as a major factor in the explanation of video game enjoyment and preference for such games [30]. The simplest and most efficient way of implementing this is through the usage of leaderboards [31]. Leaderboards track the progress of each student and display it for everyone to see, thereby creating an intrinsic need for students to compete.

2.2.3. Impact of Gamification. To be able to see the full effects of gamification, long-term study is required in both the users' acceptance of the system and their usage of it. However, based on a literature review the findings of the majority of research focusing on gamification have been positive [32].

In a research done by [9], an online-game approach in education not only improved the students' learning achievement and attitudes but also situated them in a learning state with full involvement, concentration, and enjoyment. It also improved their performance in terms of perceived ease of use and perceived usefulness. The same conclusion was reached in [33], where a digital game-based learning approach was more effective in promoting students' knowledge and more motivational than nongaming approach.

\section{Methodology}

This section of the paper focuses on the design methodology used to build the system with an explanation of the design platform, the philosophy of the interface design, and an overview of the gamification features incorporated into the system as well as the implementation of the features into the system.

3.1. Design Platform. The system was built on Microsoft's SharePoint Online, the cloud-computing version of the SharePoint platform. This particular choice was made due to prior experience with the platform as well as readily available technical help for the designing process. On top of that, SharePoint Online being a cloud based platform makes it easier to deploy the solution on a larger scale. As a plus, the developer version of the platform came at a lower cost than other options and thus was perfect for a small scale development project.

The system was built around the core components of SharePoint, making use of lists, to act as a database, and workflows to program the system logic. The majority of the system design was completed on SharePoint Designer 2013, with some of the interface features being designed on the SharePoint site itself.

To obtain access to the site as a user, the administrator of the system sends an invite to the targeted user, giving access to the user through their e-mail. This also creates a user profile for the user on the system.

3.2. Interface Design. The system interface was designed to be as user-friendly as possible, while limiting direct user interaction with the inner workings of the system. It was also designed to emphasise the gamification features that can be found within the system, creating an avenue for the users to take advantage of the game features.

3.3. Game Mechanics in System. Game mechanics are defined as methods with which the user can interact within the game world creating a form of gameplay [34]. Within the context of this system, it generally means ways with which users can experience a game-like environment. Three different game mechanics were implemented into the system to demonstrate game integration into the LMS. All 3 mechanics are commonly found within most popular games available within the market.

The first of these mechanics is leveling up through gaining experience. This helps the user to feel a sense of progression as a short-term mechanic [35], acting as a constant motivator for the user to keep going. The second mechanic is the use of player avatars. These avatars act as a representation of the user within the system and behave as a form of reward system that creates a form of extrinsic motivation for the user [35]. The third mechanic is the leaderboard. The leaderboard allows for constant, long-term motivation through the comparison of statistics with other users of the system, also in the process creating competition. 


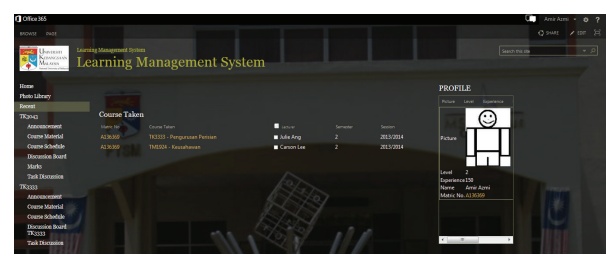

FIGURE 1: Screenshot of home page.

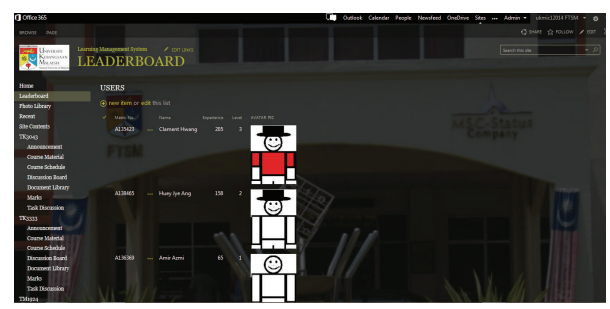

FIGURE 2: Screenshot of the leaderboard.

Although the number of mechanics implemented is limited, they provide a sound base from which to expand the list of features within the system.

3.4. Feature Implementation. In this section, the main features of the system as well as the implementation of gamification into each feature are explored. The 3 main features of the system are the main page, the leaderboard, and the task uploading modules, with each of these modules containing some element of gamification within them.

3.4.1. Main Page. When the user logs into the system, he/she will be greeted by the home page, which can be seen in Figure 1.

To the left of the screen is the navigation bar, giving direct access for the user to the courses that he/she is enrolled in, allowing him/her to access notes, announcements, and tasks set by the lecturers. In the middle is the list of courses the user is enrolled in. To the right of the screen is the user profile box, which shows the basic information of the user, such as name and identification number.

The box is also an introduction for the user to the gamification features in the system, which displays the user's level and experience points gathered in the system. Note the picture at the top of the user profile box; this is the user's avatar within the system. As the user completes assignment and gains more experience, the user will level up. This process of leveling up then changes the user's avatar to a more attractive looking avatar.

3.4.2. Leaderboard. Figure 2 is the list containing the data of all the users, presented in the form of a leaderboard.

This list shows the data of all the users in the system, such as identification number, name, experience points, level, and the user's avatar. The users are arranged according to their level and experience, and the users with the highest level are located at the top, while those with a lower level will be at the bottom.

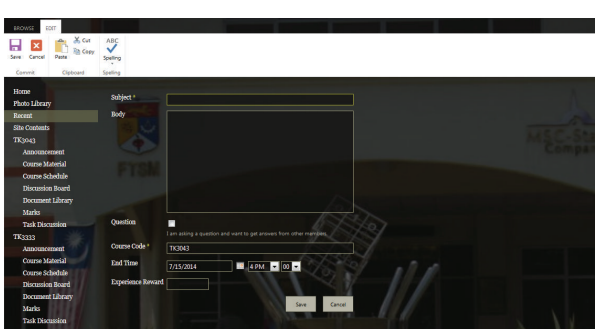

Figure 3: Assignment uploading page.

We can clearly see the differences between the avatars of the users based on their level. The user who is at level 3 has a more decorated avatar than the low-leveled character. This is a demonstration of the rewards system, where there will be a difference between the experience levels of all users depending on how much work each user has put in.

3.4.3. Task Uploading. Figure 3 shows the assignment uploading module.

This is the module used by the lecturers to upload assignments. The lecturer can set the assignment title as well as the question body along with the deadline. Furthermore, another gamification feature can be observed here, where the lecturer can set the experience reward for each assignment. The students who complete the assignment can obtain the experience reward for fulfilling the requirements of the assignment.

\section{Conclusion}

Overall, the system that has been developed tackles the issues discussed in the paper. The game elements built into the system make the use of a Learning Management System more interactive and engaging to the users. This also creates a draw for the students to spend more time with the system and builds a more fulfilling experience while using the system. This is where the gamified LMS separates itself from conventional LMSs.

There are certain weaknesses within the system, the most inherent of which is the system's incapability to work offline. This is due to the nature of an online LMS, where content can only be delivered through an Internet connection. Furthermore, the game features within the system are limited. This however can be remedied by introducing greater levels of character customisations as well as further rewards into the system. We can also add more options for gaining experience.

Currently, the system built acts more as a prototype and a proof of concept rather than a fully working system. However there are plans in place to further develop the system and further improve it, adding more game features into the system and improving the overall interaction process between the teacher and learner.

\section{Conflict of Interests}

The authors declare that there is no conflict of interests regarding the publication of this paper. 


\section{References}

[1] S. Kolowich, The Chronicle, 2013, http://chronicle.com/blogs/ wiredcampus/universities-try-mooc2degree-courses-to-luresuccessful-students-to-online-programs/41829.

[2] R. K. Ellis, A Field Guide to Learning Management Systems, American Society for Training and Development, 2009.

[3] B. Hall, E-Learning Guidebook: Six Steps to Implementing ELearning, Brandon-Hall.Com, Sunnyvale, Calif, USA, 2004.

[4] E. Dahlstrom, D. C. Brooks, and J. Bichsel, The Current Ecosystem of Learning Management Systems in Higher Education: Student, Faculty and IT Perspective, EDUCAUSE, Louisville, Colo, USA, 2014.

[5] D. McIntosh, Vendors of Learning Management and e-Learning Products, Trimeritus eLearning Solutions, 2015.

[6] G. Morgan, Faculty Use of Course Management Systems, EDUCAUSE Center for Applied Research, 2003.

[7] S. Lonn and S. D. Teasley, "Saving time or innovating practice: investigating perceptions and uses of learning management systems," Computers \& Education, vol. 53, no. 3, pp. 686-694, 2009.

[8] M. Christie and R. J. Garrote, "Lecturer engagement in the use of interactive tools in learning management systems. A Swedish case study," in Proceedings of the Australasian Society for Computers in Learning in Tertiary Education Conference (ASCILITE '11), Hobart, Australia, December 2011.

[9] G.-J. Hwang, P.-H. Wu, and C.-C. Chen, "An online game approach for improving students' learning performance in webbased problem-solving activities," Computers \& Education, vol. 59, no. 4, pp. 1246-1256, 2012.

[10] G. Ziccherman and C. Cunningham, Gamification by Design, O'Reilly Media, Sebastopol, Calif, USA, 2011.

[11] D. K. Logan and T. Neumann, Comparison of Blackboard 9.1 and Moodle 2.0, Learning Technologies Unit, Institute of Education, University of London, London, UK, 2010.

[12] J. Dunn, The 20 Best Learning Management Systems, 2012, http://www.edudemic.com/the-20-best-learning-managementsystems/.

[13] A. Bickford, 12 Common Complaints about Learning Management Systems (LMS), 2013, http://connectthinking.com.au/12common-complaints-about-learning-management-systems-lms/.

[14] S. B. Dias and J. A. Diniz, "Towards an enhanced learning management system for blended learning in higher education incorporating distinct learners' profiles," Educational Technology \& Society, vol. 17, no. 1, pp. 307-319, 2014.

[15] G. Siemens, Learning Management Systems: The Wrong Place to Start Learning, elearnspace, 2004, http://www.elearnspace .org/Articles/lms.htm.

[16] C. Barone, "The new academy," in The Net Generation, EDUCAUSE, 2005.

[17] U. D. Ehlers, "Web 2.0 - e-learning 2.0 - quality 2.0? Quality for new learning cultures," Quality Assurance in Education, vol. 17, no. 3, pp. 296-314, 2009.

[18] L. Wong and M. Fong, "Student attitudes to traditional and online methods of delivery," Journal of Information Technology Education:Research, vol. 13, no. 1, pp. 1-3, 2014.

[19] A. K. Przybylski, R. M. Ryan, and C. S. Rigby, "A motivational model of video game engagement," Review of General Psychology, vol. 14, no. 2, pp. 154-166, 2010.

[20] C. Fabricatore, "Gameplay and game mechanics: a key to quality in videogames," in Proceedings of the OECD Expert Meeting on
Videogames and Education, Enlaces-Mineduc, Santiago, Chile, 2007.

[21] S. Kolodziej, "The role of achievement motivation in educational aspirations and performance," General and Professional Education, no. 1, pp. 42-48, 2010.

[22] M. Jakobsson, "The achievement machine: understanding Xbox 360 achievements in gaming practices," Game Studies, vol. 11, no. 1, 2011.

[23] PC Magazine, "Xbox definition from PC magazine encyclopedia," http://www.pcmag.com/encyclopedia/term/54992/xbox.

[24] Microsoft, "Microsoft by the Numbers," http://news.microsoft .com/bythenumbers/index.html.

[25] H. Wang and C.-T. Sun, "Game reward systems: gaming experiences and social meanings," in Proceedings of the 5th International Conference on Digital Research Association: Think Design Play (DiGRA '11), Utrecht, The Netherlands, September 2011.

[26] M.-K. Moon, S.-G. Jahng, and T.-Y. Kim, "A computer-assisted learning model based on the digital game exponential reward system," The Turkish Online Journal of Educational Technology, vol. 10, no. 1, pp. 1-14, 2011.

[27] R. Eisenberger and L. Shanock, "Rewards, intrinsic motivation, and creativity: a case study of conceptual and methodological isolation," Creativity Research Journal, vol. 15, no. 2-3, pp. 121130, 2003.

[28] S. Boller, Using Game Mechanics and Game Elements, KnowledgeGuru, 2013.

[29] L. G. Nemerow, "Do classroom games improve motivation and learning?” Teaching and Change, vol. 3, no. 4, pp. 356-366, 1996.

[30] P. Vorderer, T. Hartmann, and C. Klimmt, "Explaining the enjoyment of playing video games: the role of competition," in Proceedings of the 2nd International Conference on Entertainment Computing (ICEC '03), pp. 1-9, Pittsburgh, Pa, USA, 2003.

[31] I. Glover, "Play as you learn: gamification as a technique for motivating learners," in Proceedings of the World Conference on Educational Multimedia, Hypermedia and Telecommunications, Victoria, Canada, 2013.

[32] J. Hamari, J. Koivisto, and H. Sarsa, "Does gamification work?a literature review of empirical studies on gamification," in Proceedings of the 47th Hawaii International Conference on System Sciences (HICSS '14), pp. 3025-3034, Waikoloa, Hawaii, USA, January 2014.

[33] M. Papastergiou, "Digital Game-Based Learning in high school Computer Science education: impact on educational effectiveness and student motivation," Computers \& Education, vol. 52, no. 1, pp. 1-12, 2009.

[34] M. Sicart, “Defining game mechanics," The International Journal of Computer Game Research, vol. 8, no. 2, 2008.

[35] J. Bycer, Motivating Mechanics in Game Design, Gamasutra, 2012, http://www.gamasutra.com/blogs/JoshBycer/20120703/ 173544/Motivating_Mechanics_in_Game_Design.php. 

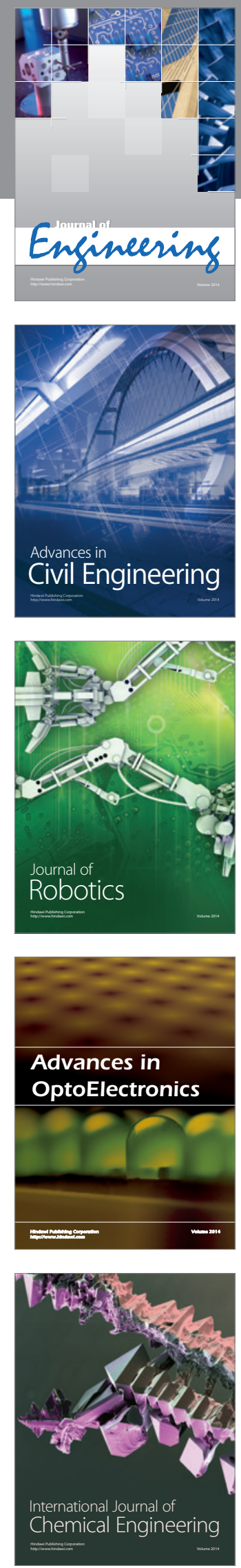

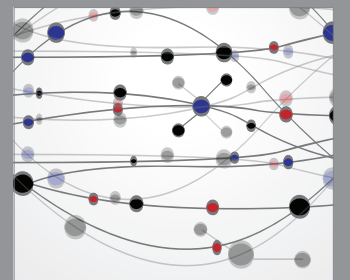

The Scientific World Journal
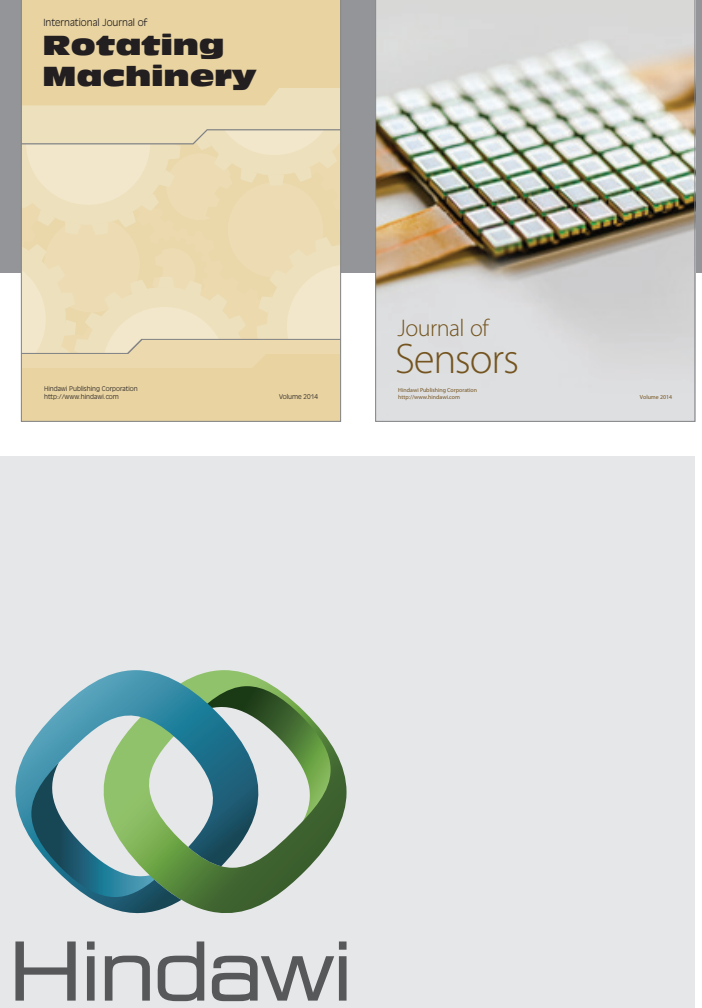

Submit your manuscripts at http://www.hindawi.com
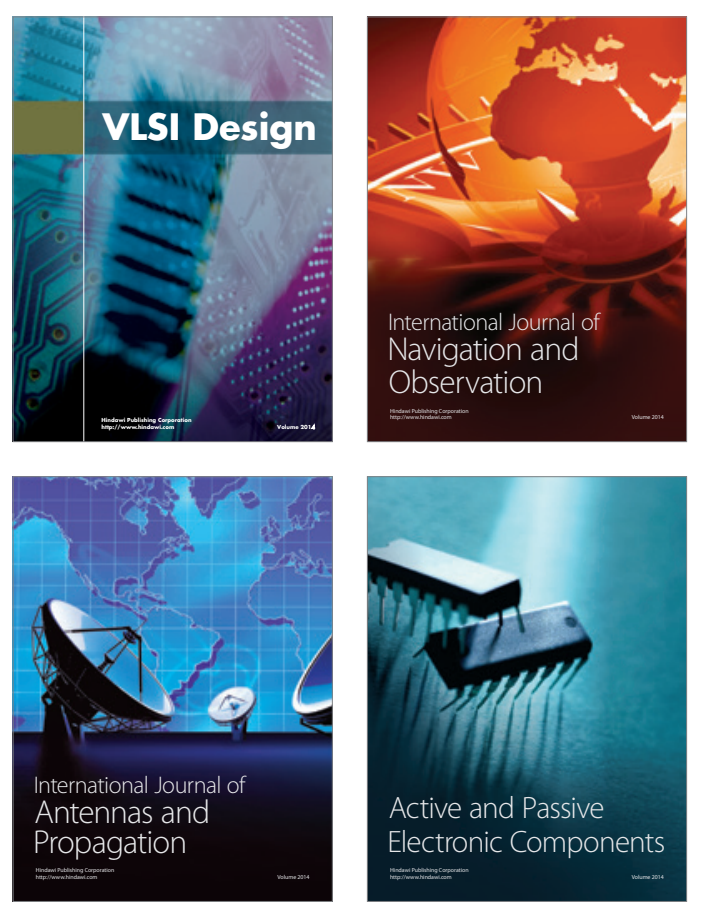
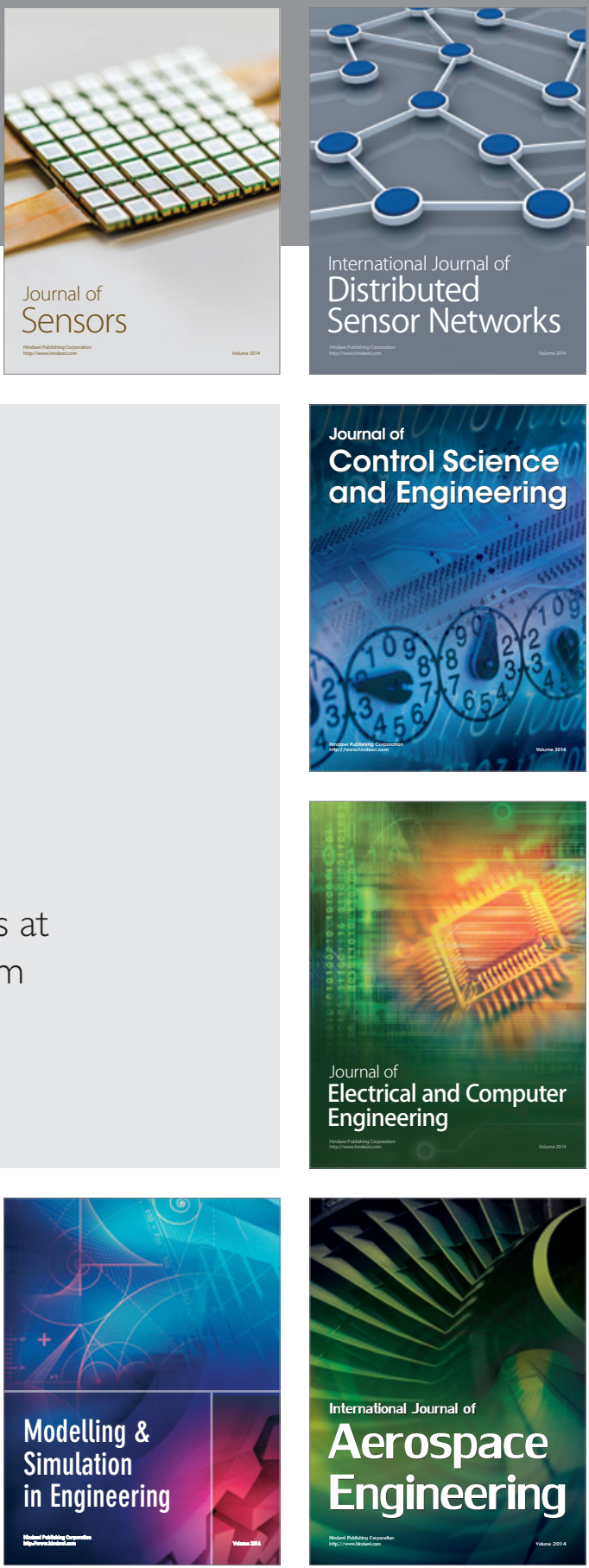

Journal of

Control Science

and Engineering
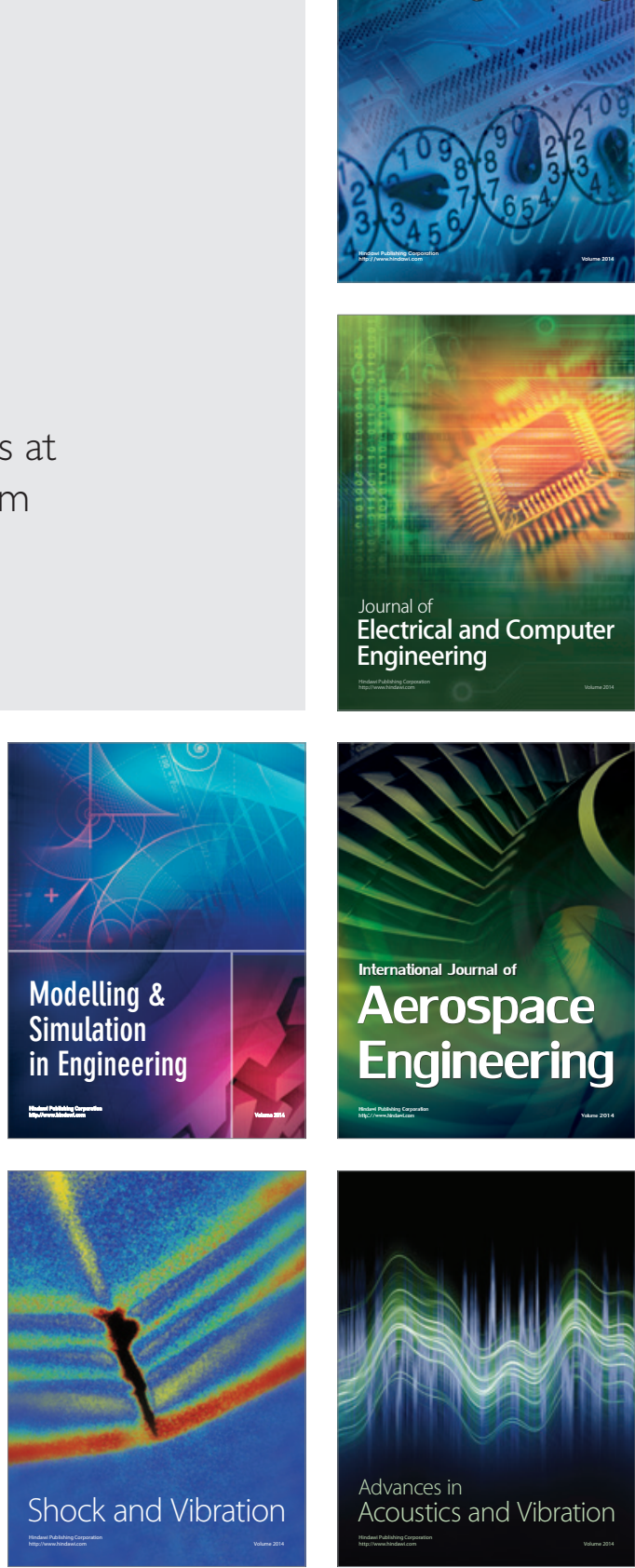